\title{
Enquête
}

Archives de la revue Enquête

5 | 1989

Biographie et cycle de vie

\section{The time structure of biographies}

\section{Chiara Saraceno}

Translator. Daniela Pedrini

\section{(2) OpenEdition}

\section{Journals}

Electronic version

URL: http://journals.openedition.org/enquete/80

DOI: 10.4000/enquete.80

ISSN: 1953-809X

Publisher:

Cercom, Éditions Parenthèses

Printed version

Date of publication: 2 March 1989

\section{Electronic reference}

Chiara Saraceno, «The time structure of biographies », Enquête [Online], 5 | 1989, Online since 27 June 2013, connection on 01 May 2019. URL : http://journals.openedition.org/enquete/80 ; DOI : 10.4000/ enquete. 80

This text was automatically generated on 1 May 2019. 


\title{
The time structure of biographies
}

\author{
Chiara Saraceno
}

Translation : Daniela Pedrini

\section{Introduction}

1 There is a way of viewing social change as resulting primarily from the diversity of organization, development and meaning of the individuals' life courses over successive time periods. This was discussed by Mannheim in his famous essay on the generations ${ }^{1}$, from the standpoint of cultural patterns, and has been recently taken up again by demographers and sociologists. The latter use the cohort concept to mean a set of individuals born within the same time span, and therefore facing social historical events at similar life stages ${ }^{2}$. For example, according to what Ryder wrote some years ago $^{3}$, we could say that social change occurs when successive cohorts experience different life courses, that is to say, they encounter different resources and constraints, both at the material and cultural level, which allow or compel them to give a different shape to their lives. This involves the way in which boundaries and attributes of the different age groups are established, the way in which sex and generational relations and membership are defined and perceived, and so forth. Changes in the job market rules and/or demand, in laws, in health conditions, fertility, survival, in political structures, and so on, by altering the individuals' life contexts affect also their direction and rhythm, which differ from those of their predecessors.

2 If, as Mannheim already pointed out, new access to society, to its rules and culture is a key feature of each new cohort, and shapes it differently from all other cohorts, remarkable changes in social structures (at national and local level), in resources and rules, lead to even more marked cohort differences, so that we cans speak of discontinuities in cultural and behavior patterns. Thus, successive cohorts will encounter new contexts, new situations resulting from these discontinuities. It is not easy to analyze the process either in terms of mere continuity or of absolute discontinuity. Nonetheless, in order to understand it, we must consider the long-term effects of the decisions made 
and of the kinds of behavior adopted by a specific cohort, as well as the interdependences among behavior patterns of different cohorts. Thus, the greater fertility of the cohort that experienced post-war prosperity results in a demand/supply imbalance on the job market experienced by its offspring as they entered adulthood during a period of technological reorganization and market transformation. Thus, the measures adopted in the financial, social and educational fields in order to cope with an expanding youth population, pose problems for successive cohorts. There are plenty of unexpected interdependencies of this kind in Western history, since each cohort develops a specific response to its own time, thus drawing the scenery for successive cohorts.

3 From what we have said so far, it will be clear that social change, viewed in terms of lifecourse variations, is not limited to the shift -and diversity- over subsequent cohorts. It interrupts, so to speak, not only intergenerational continuity, but also life-course continuity within the same cohort, in terms of its interiorized expectations, anticipatory socialization, the cognitive maps it learned in moving along its life course and in planning it. Social change, therefore, interrupts, of anyhow complicates also the patterns of transmission and communication over successive cohorts and generations. This means that different cohorts, though present at the same time on the social scene and related to each other, encounter social change at a different life stage, and with differentiated resources and constraints. As a consequence, their response, both at the behavior and cultural level, cannot be the same. This is one of the factors leading to discontinuity in experience among cohorts: not only do they encounter different situations and social historical events; adjacent cohorts, in fact, respond to the same event and the same social historical circumstances in a different way and with different consequences.

sitaneous presence of cohorts with different life courses, in terms of both values and behavior and cultural patterns, affects the relations among the various age groups and impringe on cultural transmission in times of rapid social changes. This is the case with contemporary, adult and young, cohorts in Italy.

In the analysis, of course, inter-cohort differences can neither replace nor obscure other kinds of differentiations and social inequalities. But attention must be paid to that difference, since it represents both the historical location and specific timings of interaction with social historical changes. Therefore, it helps us analyze the way in which the various kinds of social differentiation and inequality are shaped and change to become life course patterns, on the basis of the resources and constraints various segments of different cohorts encounter (see, for example, Uhlenberg, on the life courses of different cohorts of white and black women in the USA ${ }^{4}$ ).

6 Cohort membership is, therefore, one of the key elements in the temporal structure of biographies, namely, their historical time, as was noted by Elder. Within this framework, or interacting with it, life course -in its complex and intertwined timings- takes on its meaning. These considerations, and the necessity to organize them in a theoretical model, has resulted in a new approach, namely, the life course approach.

\section{The life course approach}

7 As noted by various authors ${ }^{5}$, the life course is energing not so much as a new paradigm, but as a new approach, or perspective in social sciences, whereby dimensions such as time, process and context are introduced, which are crucial to any serious study of 
human life. This approach is being applied to, and receiving theoretical and methodological contributions from different fields of human sciences -e.g., life span psychology, anthropology, social history (especially the studies of family history), and demography.

8 In the light of the review of the main features of the life course approach in social sciences performed by Featherman ${ }^{6}$, we could say that this approach, as it has recently developed, raises the problem of time and of change over time in two ways: as historical time, and therefore as the individuals' location in it (the cohort concept) and as life time, whereby biography is viewed as developing through time, that is, as a process of change and transformation, and not only of evolution ${ }^{7}$.

9 As Hareven writes,

"The life course approach offers a comprehensive, integrative approach, which allows us to interpret individual and family transitions as part of a continuous, interactive process of historical change. It helps us to view an individual life transition [...] as part of a cluster of concunent transitions and sequence of transitions that affect each other. It views a cohort not only as belonging to its specific time period, but also located in earlier times, its experience shaped, therefore, by different historical forces [...] The life course approach links individuals' biographies with their collective behavior as part of an ongoing continuum of historical change."

10 It is true, as Featherman himself notes, that the interest in the life course, that is, in the pathways of biographies, in the events that affect and impringe on them and in their variations, emerged in other periods as well, particularly in the forties and, later, in the sixties, when social change was more clearly marked and subject to investigation by social sciences.

11 There are, however, important differences in today's life course approach, as it has been developed in the studies of social history ${ }^{9}$, anthropology ${ }^{10}$, demography ${ }^{11}$, life span psychology ${ }^{12}$, social psychology ${ }^{13}$, and sociology ${ }^{14}$.

12 The main features of this approach refer on the one hand to the attention paid to cohort events, to cohort membership of individuals experiencing the transformations under study, and therefore, for their social historical location; on the other hand, to the stress given to the entire life course as made up of different ages or stages, as well as specific experiences (occupational, marital, parental, son/daughter, friend, and so forth). As a consequence, the latter are not viewed in terms of static roles, or as evolutionary processes alone; they are rather viewed as careers, or trajectories, whose timing and structures are not shaped by inner rules or rhythms, but stem from the interdependence and interaction with social historical events.

13 The perspective of trajectories and their dynamics shifts the interest in life course analysis from the so-called life events -viewed as punctual events, both normative and exceptional- to life transitions: to the processes whereby given life events take on special meanings and have specific impacts on individual stories ${ }^{15}$. It is important to know not only if and when, in terms of age, an individual completed his/her education, married, got a job, divorced or had a child, but also the resources he/she had in terms of options, of reference norms of previous history in that or other trajectories, and the timing of the event in relation to other events and transitions: parenthood may come before or after marriage, or out of marriage; employment may come before or after marriage. The different sequences give a different meaning to individual transitions and life events. 

moving. of events.
The study of transitions shows us the interdependence of trajectories. Each transition, in fact, is linked not only to the life history of a specific trajectory, which, in turn, affects its future direction, but also to the resources and constraints of other interlocking pathways or careers -to their timetables, timings, transitions and relations.

The study of women's life courses proved particularly valuable in showing the relevance of this interdependence. But this is true for both men and women, though a particular balance, the direction of interdependences, the impact of interlocking effects may vary, as they do, in fact, between the sexes (this is where the life course approach proves to be particularly valuable in order to understand how the sex/gender system works and changes in a given society); they vary also among social classes and strata, since each trajectory -with its own timetable and more or less normative transitions- is marked by resources and constraints which differ according to sex, class, ethnicity, race, and so forth, in so far as they have a different access to social resources. A man's decisions concerning his work career -or the effects of events and decisions within this trajectoryhave an impact on and are affected by events occuring in other trajectories in which he is

However, we often forget this seemingly obvious phenomenon, and male decisions concerning employment are interpreted as if they had no relation with other life trajectories. As Long and Porter note ${ }^{16}$, we speak of "two roles", both at the research and cultural-political level, only when analyzing working women. It is, instead, necessary to show the specificity of this interlocking and its impact on the life course in terms of cohort, sex and any other important social membership.

As both Elder and Featherman note, the framework of the study of transitions is rooted in the works of the authors of the Chicago school, especially in Thomas's, but also in Burgess's and Waller's. The importance of historical time, however, as experienced in the so-called cohort historical approach in the life-course study, introduces a more sophisticated temporal perspective in the study of transitions and, at the same time, prevents us from falling into a methodological individualism which may result from focusing our attention exclusively on individual biographies. By using the cohort perspective, in fact, individual life histories are located within historical time, and are viewed not only as a starting point, but as a particular way in which collective history -as a succession of events, a resource structure, as well as a set of cultural and normative patterns- is encountered during the life course.

8 The temporal perspective, whereby the dimensions of historical time, life time and social time are taken into account, should enable us to point to different aging patterns or life courses, in different historical periods. This does not mean that is should replace, as an alternative explicative method, other kinds of social differentiation; on the contrary, the study of life course within its historical framework enables us to understand the impact of social differentiation and inequality (in relation to sex, social class or stratum, geographical location, etc.) on life course patterns. In fact, as Elder states ${ }^{17}$, not all individuals experience the same transitions at the same point in time and with the same sequence, although in each period there are social and normative timetables and timings

Elder and Rockwell ${ }^{18}$ analyze, for instance, the impact of the economic crisis of 1929 (as for behavior patterns, options, values, occupational and familial status, as well as political 
structures and social security) on the subsequent life courses of individuals who had experienced the crisis as young children. They so conclude:

"Life prospects are influenced at birth by family position within the class structure, by genetic transmission and by the historical context of one's birth cohort. Differential life opportunities are associated with membership in birth cohorts that vary according to size, composition and historical experience; and with age and class position at the point of historical events. Such variations are also likely by class position within specific cohorts to the extent that it structures exposure to change and adaptive resources."

In the life course perspective, individuals belonging to a specific age or life stage are viewed both as historical actors, that is, located in a specific historical context, and as individuals experiencing a somewhat continuing transition; thus, it is necessary to understand their pathways in terms of both behavior and self-perception. The individuals, during their life courses, develop a different balance among their various trajectories, in so far as they develop different interest and attribute different meaning and relevance to what they do. Therefore, they (according to Levinson's life structures ${ }^{19}$ ) develop different life structures which are the skeleton of the life course. Each life structure is by no way neutral and affects present and future life periods, both at a practical and symbolic level, but it is not the ultimate, nor is it totally predictive of the future.

21 At this point emerges the active role of the individual shaping his/her own biography. Priorities and meanings, as well as the evaluation of possible pathways and strategies, do not result merely from external pressures, from social norms and circumstances. As a matter of fact, an individual must constantly make evaluations and decisions on the basis of the resources and information available, of his/her personal history, as he/she perceives and elaborates it and as it produces his/her specific worldview.

In this sense, by using the life course concept, we avoid a fragmentary and casual vision of biography, as well as a monolithic and rigid concept of biography, viewed as a coherent and specific destiny (what Bertaux calls the "ideology of biography"20). Continuity, instead, stems from the cumulative experience of earlier life stages, and from the patterns developed by the individual in order to face new events -even if a given event may lead to specific responses, differing from the established routine modes, and therefore start new cumulative/learning processes ${ }^{21}$.

In this regard, Pearlin's observations ${ }^{22}$ based upon his study of stress factors and their impact on the various life stages and contexts, are extremely interesting. He criticizes any linear and orderly viewpoint of life course, and also life span theories ${ }^{23}$, whereby individuals are seen as moving through a set of normative crises, which are markers between the various stages. He states that stress conditions and emotional turmoils or, anyway, the need for radical change, do not necessarily result from normative events and transitions. On the contrary, they are usually caused by "abnormal", unexpected events, which occur off the normatively established timetable and cognitive maps -such as the early death of a dear person, divorce, being fired or unemployment, falling in love off time, and so forth. In saying so, Pearlin does not mean that normative events and transitions are not important for the individual's biography; instead, being expected, they give rise to anticipatory adaptation (and, therefore, have a longer and less visible history); on the other hand, by stressing the normality of the life course, they highlight its continuity rather than its discontinuity, its matter-of-factedness rather than its active production. When a given event represents a break from expected and existing 
circumstances and relations, the individual is compelled to explicate, first to himself, his own values and intentions, he must put them to trial, and often even change them ${ }^{24}$.

Therefore, it is the subjective perception and definition of the circumstances that gives sense to behavior patterns, thus becoming an integral part of the life course. This entails that two formally similar life courses, as for behavior patterns, may be different as for the subject's interpretations and intentions.

It is clear that this approach, while offering new opportunities for investigation, poses complex methodological and measurement problems, as Watkins, too, noted ${ }^{25}$. Owing to the difficulty in solving these problems, the life course concept remains a perspective, rather than a perfected paradigm with a well developed methodology. But this perspective raises some questions and points the way to further investigation which cannot be easily ignored.

This perspective and the methodological problems it raises, makes us aware of the necessity of an interdisciplinary approach and of different sources and instruments of investigation. Apart from measuring and testing independent temporal and social variables, we must reconstruct actual behavior patterns. Therefore, we need a set of quantitative data, possibly based upon a wide and representative population sample on sets of inter- and intra-cohort behavior patterns. On the other hand, we must reconstruct the prevailing normative patterns and, where necessary, their differentiation by sociocultural groups. Finally, reconstruction of the individual's motivations, perceptions, interpretations and decision-making strategies is necessary. Hareven ${ }^{26}$ states that we should develop an ideally integrated approach of individual oral history accounts and collective life histories (cohort macrobiographies) based upon demographic and institutional data. This would help us understand life-course-related norms and expectations in a given society, how they have affected and affect the individual's decision-making processes, and, finally, how the various social groups react to and are aware of them.

In this perspective, the biographical approach can be a valuable instrument of investigation. The focus on individual life paths, in fact, enables us not only to understand and point to the possible interlockings and interrelations within and among the various trajectories, but also to relate behavior patterns to perceptions and intentions, at least within the restricted sample which is compatible with this approach.

No doubt, this method, or rather, this set of methods, is not free of risks and problems, which become even more complex in a longitudinal study; only the latter, however, allows for the temporal perspective and control inherent in the concepts of trajectory and transition. The theorical and methodological problems stemming from the so-called biographical method and from the evaluation of its procedures, are not discussed here, since they go beyond the scope of this paper ${ }^{27}$. 


\section{NOTES}

1. K. Mannheim, "The problem of generations", in Essays on the Sociology of Knowledge, London, Routledge \& Kegan Paul, 1952.

2. On the difference between "cohort" and "generation", see D. Kertzer, "Generation as a sociological problem", Annual Review of Sociology, 9, 1983, p. 125-149.

3. N. Ryder, "The cohort as a concept in the study of social change", American Sociological Review, 30, 1965, p. 843-861.

4. P. Uhlenberg, "Cohort variation in family life cycle experiences of U.S. females", Journal of Marriage and the Family, May 1974.

5. G. Elder Jr., "Family history and the life course: an appraisal. 1975-1983", Paper presented at the conference on Family History, Clark University, November 14-15, 1983 ; T. K. Hareven \& K. J. Adams, eds, Aging and Life Course Transitions. An Interdisciplinary Perspective, New York, Guilford Press, 1982 ; M. W. Riley, R. P. Abeles \& Michael S. Teitelbaum, eds, Aging from Birth to Death, II. Sociotemporal Perspectives, Boulder, CO, Westview Press, 1982.

6. D. L. Featherman, "Life span perspectives in social science research", in P. Baltes \& O. Brim, eds, Life Span Development and Behavior, New York, Academic Press, 1983, vol. 5.

7. C. Saraceno, ed., Età e corso della vita, Bologna, Il Mulino, 1986.

8. T. K. Hareven, "The life course and aging in historical perspective", in Id. \& K. J. Adams, eds, Aging and the Life Course Transitions, p. 7.

9. T. K. Hareven, Transitions. The Family and the Life Course in Historical Perspective, New York, The Academic Press, 1978 ; J. Modell, F. F. Furstenberg \& T. Hershberg, "Social change and transitions to adulthood in historical perspective", Journal of Marriage and the Family, 1, Autumn 1976.

10. D. Kertzer \& J. Keith, eds, Age and Anthropological Theory, Ithaca, NY, Cornell University Press, 1984.

11. N. Ryder, "The cohort as a concept..." ; and "The demography of youth", in J. Coleman, ed., Youth. Transition to Adulthood, Chicago, University of Chicago Press, 1974.

12. P. Baltes \& K. W. Schaie, eds, Life Span Developmental Psychology. Personality and Socialization, New York, Academic Press, 1973 ; P. Baltes, ed., Life Span Development and Behavior, New York, Academic Press, 1978, vol. 1 ; P. Baltes \& O. G. Brim, eds, Life Span Development and Behavior, New York, Academic Press, 1979-85, vol. 2-7.

13. B. Neugarten, ed., Middle Age and Aging, Chicago, Chicago University Press, 1968 ; B. Neugarten \& N. Datan, "Sociological perspectives and the life cycle", in P. Baltes \& K. W. Schaie, eds, Life Span Developmental Psychology..., 1973.

14. M. Riley, M. Johnson \& A. Foner, Aging and Society, III. A Sociology of Age Stratification, New York, Russel Sage Foundation, 1972; M. Riley, "Age strata in social systems", in R. H. Binstock \& E. Shanas, eds, Handbook of Aging and the Social Sciences, New York, Van Nostrand Reinhold, 1976 ; M. Riley, "Introduction. Life course perspectives", in Aging from Birth to Death. Interdisciplinary Perspectives, Boulder, Westview Press, 1979, p.3-13; M.W. Riley, R. P. Abeles \& Michael S. Teitelbaum, eds, Aging from Birth to Death..., 1982 ; G. H. Elder Jr., Children of the Greast Depression, Chicago, The University of Chicago Press, 1974 ; Id., "Age differentiation and the life course", Annual Review of Sociologie, 1, 1975 ; Id., "Approaches to social change and the family", in J. Demos \& A. Boocock, eds, Turning Points, Chicago, The University of Chicago Press, 1978; Id., "Perspectives on the life course", in Id., ed., Life Course Dynamics. Trajectories and Transitions, 1968-1980, Ithaca, NY, Cornell University Press, 1984.

15. G. H. Elder Jr., ed., Life Course Dynamics... 
16. J. Long \& K. L. Porter, "Multiple roles of midlife women. A case for new direction in theory, research and policy", in G. Baruch \& J. Brooks-Gun, eds, Women in Midlife, New York, Plenum Press, 1984.

17. G. H. Elder, "Family history and the life course..." ; and Id. "Perspectives on the life course".

18. G. Elder Jr. \& R. Rockwell, "Economic depression and postwar opportunity in men's lives. A study of life patterns and health", in R. G. Simmons, ed., Research in Community and Mental Health, Greenwich, CT, JAI Press, 1979, vol. 1, p. 249-303.

19. D. Levinson, The Seasons of a Man's Life, New York, Knopf, 1978.

20. D. Bertaux, "From the life history approach to the transformation of the sociological practice", in Id., ed., Biography and Society, Berkeley, Sage, 1981.

21. L. Rosenmayr, "Biography and identity", in T. K. Hareven \& K. J. Adams, eds, Aging and Life Course Transitions..., p. 27-54 ; E. Glen Jr., "Stressful times in children's lives”, paper presented at the Interdisciplinary Workshop on Human Development, Ithaca, NY, Cornell University, May 14-15, 1985.

22. L. I. Pearlin, "Discontinuities in the study of aging", in T. K. Hareven \& K. J. Adams, eds, Aging and Life Course Transitions..., p. 55-74.

23. E. Erikson, Childhood and Society, New York, Norton, 1950 ; Id., Identity and the Life Cycle, New York, International University Press, 1954 ; D. Levinson, The Seasons of a Man's Life.

24. D. Belle, ed., Lives in Stress. Women and Depression, Beverly Hills, Sage, 1982 ; K. Gerson, Hard Choices, Los Angeles, University of California Press, 1985.

25. S. Watkins, "On measuring transitions and turning points", in Historical Methods, Summer, 1980 ; see also G. H. Elder Jr., Children of the Greast Depression.

26. T. K. Hareven, "The life course and aging in historical perspective", in Kurt W. Back, ed., Life Course. Integrative Theories and Exemplary Populations, Boulder, CO, Westview Press, 1980 ; see also L. Rosenmayr, "Biography and identity".

27. I discussed this in "Corso della vita e approccio biografico", Quaderno del Dipartimento di Politica sociale (Università di Trento), 9, 1986. 